\title{
Environmental Management: Past and Future Communications
}

\author{
Virginia H. Dale
}

Received: 5 May 2014/ Accepted: 9 May 2014/Published online: 29 May 2014

(C) Springer Science+Business Media New York (outside the USA) 2014

Although it seems only a short time ago, it was 2001 when I became Editor-in-Chief of the journal, Environmental Management. What drew me to engage with this journal is that it covers the field of "applied ecology in the widest sense, without regard to disciplinary boundaries" (Dale 2002). Over the years, I had the privilege of interacting with environmental scientists from around the world, who are committed to sharing their ideas and experiences, and the opportunity to read many outstanding papers on applied ecology.

The first paper in the initial issue of Environmental Management said it was "an auspicious time to start a journal devoted to something called 'environmental management," "for its definition was still in the future (Harkins 1976). Clearly the field has come a long way since then. Environmental management is now so well defined that there are several texts about it, and classes on the topic are regularly taught. The many papers published in the journal Environmental Management have been an important part of the development of this discipline.

Now in its 38th year, Environmental Management is clearly a leader in publishing new ideas and research in applied ecology. The quality of the journal largely derives from the strength and dedication of the Editorial Board who has both attended to the vision of the field of environmental management and empathized with authors' challenges. It was my pleasure to have worked with Rebecca Efroymson who joined me as co-Editor-in-Chief in 2010 (Dale 2010). I also want to thank the authors for their perseverance in the face of the challenges in

V. H. Dale $(\bowtie)$

Environmental Sciences Division, Oak Ridge National

Laboratory, Oak Ridge, TN 37831-6036, USA

e-mail:dalevh@ornl.gov conceiving of studies, carrying them out with attention to detail, and writing up the results and discussion with clarity. Each of these tasks requires different skills and persistence. But the thousands of manuscripts published in the journal and subsequent references to those analyses attest to the value of this body of work.

Over my 13 years as Editor, I learned much about science communication and writing from both good and poor examples as well as from the professional editors with whom I worked. Linda O'Hara served for many years as the Editorial Assistant for the journal and helped not only with identifying good reviewers and moving manuscripts through the review process but also in ensuring that each manuscript did a good job in communicating the underlying science. Publishing results is a key part of the scientific process, and most scientists can learn a great deal by working with professional editors. My major lessons about writing scientific papers are summarized below.

- Scientific papers are not mystery novels. It is important to present the key results in the abstract of the manuscript and to have the introduction of the paper make clear both the impetus for the study and what is be presented in the manuscript.

- Authors need to give the greatest attention to the parts of paper most likely to be read. Most people do not read a scientific paper from beginning to end but rather first focus on the title, then the abstract, and next the figures and tables. If the information presented is of interest, then the conclusion will be perused. Only those studies that have particular pertinence to the reader will be read in their entirety.

- Organization of the material is critical. Almost all scientific papers should follow the standard format: introduction, methods, results, discussion, and conclusion. 
Authors should check that the methods are complete and that most figures and tables are presented in the results section.

- Each paragraph should start with a strong topic sentence, which presents the main idea and hence is an overview of what is to come. The concluding sentence should summarize the paragraph and provide a logical flow to the next one.

Soon to enter its fourth decade of publishing, Environmental Management should retain its emphasis on high quality science and communication. Publishing is a critical part of the scientific process. Presenting and debating results and ideas are essential parts of developing new understanding about the environment. The journal improves cross-disciplinary communication and makes ideas and results available to environmental practitioners. Managing natural resources in a sustainable way is now a global vision that builds from many detailed analyses such as those published in the journal. Scientific publications provide a means to develop, communicate, and debate key principles for effective stewardship of Earth's resources.

Acknowledgments Suggestions by Rebecca Efroymson on an earlier draft of this editorial are appreciated.

\section{References}

Dale VH (2002) Environmental Management fosters enhanced communication through cross disciplinary studies. Environ Manag 29:1-2

Dale VH (2010) Environmental Management welcomes a new face and reinforces its focus on science-based stewardship. Environ Manag 45:1243-1243

Harkins JP (1976) Thou canst not stir a flower. Environ Manag 1:4-5 